\title{
Approach to teaching and learning during COVID-19 global pandemic
}

\author{
J.A. Dujaili*, A.Q. Blebil, A.H. Mohammed \\ School of Pharmacy, Monash University Malaysia, Malaysia
}

\section{Keywords}

Online Delivery

Emergency Response

Movement Control Order

Malaysia

*Corresponding author:

juman.dujaili@monash.edu
Summary: Due to the threat of COVID-19, universities across Malaysia are facing decisions about how to continue teaching and learning whilst keeping their faculty, staff, and students safe from a public health emergency that is fast moving and not well understood. Monash University Malaysia is no exception and have opted to cancel all face-to-face classes, including laboratory and other learning experiences, and have mandated that faculty move their units online to help prevent the spread of the virus that causes COVID-19. Approaches as well as the remedial measures undertaken by the School of Pharmacy, Monash University Malaysia, with regards to teaching and learning (T\&L) activities during and beyond the execution of the Movement Control Order (MCO) in Malaysia are discussed below.

\section{Background and Context}

At Monash Pharmacy, the established way of teaching is ideally suited to online delivery. The use of online learning platforms such as Moodle and MyDispense were incorporated into the teaching design over several years. Prior to COVID-19 social distancing requirements, every pharmacy unit at Monash University Malaysia had already been designed to make use of online learning platforms in order to broaden the range of resources available to students and allow types of interactivity never possible in 'traditional' teaching modes. Online learning platforms allow students to review, revise, and revisit the lectures and weekly study resources online at any time to make sure they get all the information they need.

To ensure uninterrupted learning and high-quality education for Monash University Malaysia students during the COVID-19 global pandemic, staff had to quickly adapt and deliver the course solely via online learning platforms. Staff came up with a full online conversion of all face-to-face activities in term one, including lectures, workshops and assessments. The opportunity was also taken to improve and further refine the quality of the content. Staff enhanced the learning activities to incorporate the impact of the pandemic and to install values of compassion and professional responsibility in the students, who are the future generation of frontline healthcare professionals.

\section{Educational Description}

To provide the students with meaningful learning experiences despite the unique challenges of learning in lockdown, the authors, with help from the faculty of Pharmacy and Pharmaceutical Sciences at Monash University Australia, created an online teaching schedule that is as comprehensive as their original face-to-face sessions. Students carry out learning activities on a specific topic every week beginning with selfdirected learning through to a conclusion lecture as follows:

1. Discovery material (i.e. guided online learning): this is dedicated to self-directed learning from the material developed to enhance students' understanding of the topic of the week. The contents are already established on Moodle; hence, no major modification has been made. 
2. Interactive lectures (ILs): students complete a series of high-quality activities and watch feedback videos via the online ILs. The activities are presented in the form of Moodle quizzes and arranged as information pages with short pre-recorded videos. ILs are interspersed with tasks to ensure the coverage of the planned learning outcomes of the topics.

3. Workshops: information is arranged in Moodle books as usually done before COVID-19 pandemic; however, the mode of delivery is changed to either: synchronous Zoom workshops with breakout rooms (students were asked to participate in facilitated live Zoom workshops and refine their knowledge and clinical skills by working on case studies with their peers under the supervision of the facilitators) or asynchronous (e.g. Moodle quizzes, filmed role-plays, worksheets, and the use of Monash MyDispense software).

4. Close-the-loop lectures (CtLs): these are recorded Zoom webinars to reinforce the students learning and give them general feedback on their performance in online activities throughout the week. Students were also actively engaged in discussion forums and PollEverywhere to get clarification on different topics.

Moreover, various support programmes were available during lockdown to address the different academic and developmental needs of the students, including skills coaching, Peer Assisted Study Sessions (PASS) mentoring programmes and fortnightly touch-base virtual sessions via Zoom to answer any outstanding questions students had. The authors also emphasised the tools available to help students work remotely and what to do if accessing them was a challenge. In addition, they made a point of directing students to other campus resources, including library resources, academic advisers, and counselling services.

\section{Outcomes and Recommendations}

Looking for opportunities and purpose requires educators to approach work differently during a global pandemic. Although the University has set aside some of its academic traditions to deal with the acute phase, staff's strength as long-term planners will be critical as the chronic phase of COVID-19 is entered. The pandemic has forever changed pharmacy education; presenting an opportunity to make it better. Pharmacy educators have a collective responsibility to prepare students to be practice-ready and team-ready for now and for the next global pandemic (Lyon, Christopoulos, \& Brock, 2020).

\section{References}

Lyon, K., Christopoulos, A., \& Brock, T. (2020). Sustainable Pharmacy Education in the Time of COVID-19. American Journal of Pharmaceutical Education, 84(6), 667-672. https://doi.org/10.5688/ ajpe8088 